\title{
Blood and brain concentrations of mercaptans in hepatic and methanethiol induced coma
}

\author{
H AL MARDINI, K BARTLETT, AND C O RECORD \\ From the Gastroenterology Unit and Department of Clinical Biochemistry and Metabolic Medicine, Royal \\ Victoria Infimary and University of Newcastle upon Tyne
}

SUMMARY It has been suggested that mercaptans are important factors in the pathogenesis of hepatic encephalopathy. Using a gas liquid chromatographic technique which uses propanethiol as internal standard and a sulphur specific detector, blood methanethiol concentration was found to be significantly risen in encephalopathic patients with liver disease $(13 \cdot 2 \pm 1.0 \mathrm{nmol} / \mathrm{ml} ; \mathrm{n}=47)$ compared with control subjects $(5 \cdot 7 \pm 0 \cdot 3, n=29 ; \mathrm{p}<0.05)$ and non-encephalopathic patients with liver disease $(7 \cdot 7 \pm 1 \cdot 1, n=35 ; p<0 \cdot 05)$ but ethanethiol and dimethylsulphide concentrations were similar in the three groups. Blood methanethiol, however, was not clearly related to coma grade, similar values being found in deeply comatosed patients to those showing only mild cerebral dysfunction. When rats were injected with $40-120 \mu \mathrm{mol}$ methanethiol a range of responses was obtained which varied between normal consciousness and coma. The minimum blood concentration of methanethiol associated with coma $(200 \mathrm{nmol} / \mathrm{ml})$ was at least 10 -fold greater than in patients with hepatic encephalopathy but brain concentrations were similar in comatose rats and those which remained awake. Blood methanethiol concentrations were similar in control and germ free rats and did not rise in cirrhotics or controls after ingestion of $2 \mathrm{~g}$ methionine. It is concluded that while methanethiol may accumulate in hepatic coma, it is unlikely to be of major pathogenetic importance. Endogenous mercaptans are unlikely to originate from bacterial metabolism in the gut.

The precise pathogenesis of hepatic encephalopathy is poorly understood although a number of substances have been implicated because they cause coma in experimental animals. These include ammonia, short chain fatty acids and mercaptans and synergism between these substances has been shown. ${ }^{1}$ Other possible mechanisms include an accumulation of false neurotransmitters such as octopamine and a fall in normal neurotransmitters such as dopamine and noradrenaline. ${ }^{2}$ Recent studies in animals, however, have shown a marked fall in cerebral neurotransmitters after intraventricular injection of octopamine while no apparent change in consciousness was observed. ${ }^{3}$ Furthermore noradrenaline concentrations were similar in the brains of patients with hepatic encephalopathy compared with controls while

Address for correspondence: Dr C O Record, Gastroenterology Unit, The Royal Victoria Infirmary, Queen Victoria Road, Newcastle upon Tyne NE1 4LP.

Received for publication 31 May 1983 dopamine concentrations were normal or increased. ${ }^{4}$ Brain octopamine concentrations were not significantly greater than in controls. ${ }^{4}$

Mercaptans were first implicated in hepatic coma when methanethiol was isolated from the urine. ${ }^{5}$ Subsequent investigations showed increased concentrations of methanethiol ${ }^{6}$ and dimethylsulphide ${ }^{7}$ in the breath of patients with hepatic failure. In a recent study methanethiol was significantly increased in the blood of patients with hepatic encephalopathy, $93 \%$ of encephalopathic patients having values outside the normal range. ${ }^{8}$ Ethanethiol also appears to be significantly increased. ${ }^{9}$ In the present study we have assessed concentrations in blood of the mercaptans methanethiol, ethanethiol, and dimethylsulphide in patients with different grades of hepatic coma and compared them with values in rats in coma after an intraperitoneal injection of methanethiol. We have also compared brain concentrations of mercaptans in rats with experimental liver damage with methanethiol induced coma. As the origin of blood mercaptans is 
at present unclear we have also assessed changes in blood concentrations in patients with cirrhosis after ingestion of methionine and examined mercaptan concentrations in germ free rats.

\section{Methods}

\section{PATIENTS}

Blood was obtained by standard venepuncture from patients with hepatic encephalopathy, patients with liver disease but no evidence of encephalopathy, and control subjects. All decompensated patients with hepatic encephalopathy were studied irrespective of the aetiology of the liver disease or whether acute or chronic. Four $1 \mathrm{ml}$ aliquots of whole blood were added to ice cold $7 \mathrm{ml}$ septum bottles and immediately frozen before assay by gas liquid chromatography as previously described. ${ }^{10}$ The frozen blood samples in closed septum bottles were thawed, $200 \mu$ l propanethiol internal standard solution $(100 \mu \mathrm{l}$ propanethiol in $5 \mathrm{ml}$ methanol diluted to $42 \mu \mathrm{mol} / \mathrm{l}$ with water) added to each sample via a slide valve and septum (Minnert), shaken for 30 seconds and refrozen. The blood samples were then treated with zinc and phosphoric acid to obtain maximal release of mercaptans. For this $1 \mathrm{ml}$ zinc slurry $(10 \mathrm{~g}$ zinc dust stirred in $50 \mathrm{ml}$ water at $55^{\circ} \mathrm{C}$ ) and $0.5 \mathrm{ml}$ of $3.3 \mathrm{~mol} / 1$ phosphoric acid were added to the sample and heated at $60^{\circ} \mathrm{C}$ for 10 minutes. To sample the gas phase $1 \mathrm{ml}$ air was injected into the sample bottle and $1 \mathrm{ml}$ withdrawn and injected onto the gas chromatograph. Gas samples were analysed using a Carlo Erba model FV 350 gas chromatograph fitted with sulphur specific detector. A glass column $(2.5 \mathrm{~mm} \times 3 \mathrm{~mm}$ internal diameter) packed with $20 \%$ SE30 on $60-80$ Chromosorb $\mathbf{P}$ was used. The gas flow rates were as follows: nitrogen carrier gas $130 \mathrm{ml} / \mathrm{min}$, hydrogen $45 \mathrm{ml} / \mathrm{min}$, oxygen $12.5 \mathrm{ml} / \mathrm{min}$, air $15 \mathrm{ml} / \mathrm{min}$. The column was run isothermally at $36^{\circ} \mathrm{C}$ and the injection port and detectors maintained at $100^{\circ} \mathrm{C}$. Samples were injected onto the column with a $1 \mathrm{ml}$ A2 pressure lock gas syringe (Precision Sampling Corporation, USA). The chromatograph was fitted with both a pen recorder and integrator (Infotronics, UK Model 308).

Encephalopathic patients were graded for depth of coma, using the classification of Trey and Davidson. ${ }^{11}$ Where possible sequential estimations were undertaken. To investigate the origin of mercaptans in blood, five fasting outpatients with stable biopsy diagnosed cirrhosis gave informed consent to ingest $2 \mathrm{~g}$ methionine in tablet form. Blood was obtained at hourly intervals over the next four hours. For estimation of blood mercaptan concentration in germ free rats, blood was obtained by decapitation. Brain mercaptan estimations were undertaken on $200 \mathrm{~g}$ rats treated with a lethal dose of carbon tetrachloride $(3.2 \mathrm{~g} / \mathrm{kg})$. The rats were killed 24 hours after carbon tetrachloride administration, when liver function tests were severely deranged or sooner if they appeared moribund. The majority of rats treated with this dose of carbon tetrachloride died within the following 48 hours. The cortex was placed on ice, weighed and added to four parts Tris $\mathrm{HCl}$ buffer $(\mathrm{pH} \mathrm{7.0)}$ before sonication. One millilitre aliquots were subsequently added to septum bottles and treated in the same way as whole blood.

Methanethiol induced coma was induced by intraperitoneal injection of a solution of methanethiol in water. The latter was prepared by passing a stream of methanethiol gas (Cambrian Gases, Croydon, Surrey, UK) through water as previously described. ${ }^{10}$ The dose of methanethiol administered varied between 40 and $120 \mu \mathrm{mol}$.

STATISTICAL METHODS

Values quoted are mean \pm SEM. $P$ values refer to the Student's $t$ test or the Mann-Whitney U test where appropriate.

\section{Results}

BLOOD MERCAPTANS IN PATIENTS FOLLOWING INGESTION OF 2 G METHIONINE

Concentrations of blood methanethiol (Fig. 1), ethanethiol and dimethylsulphide (Fig. 2) after ingestion of $2 \mathrm{~g}$ methionine are shown. There were no significant differences over the observation period.

\section{BLOOD AND BRAIN MERCAPTANS IN GERM FREE} RATS

Blood methanethiol, ethanethiol, and dimethylsulphide concentrations were similar in germ free

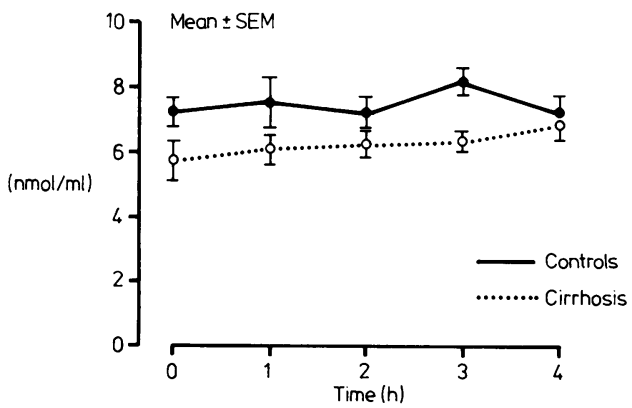

Fig. 1 Blood methanethiol after ingestion of $2 \mathrm{~g}$ of methionine by patients with cirrhosis and controls. 
Fig. 2 Blood ethanethiol and dimethylsulphide after ingestion of $2 \mathrm{~g}$ of methionine by patients with cirrhosis and controls.

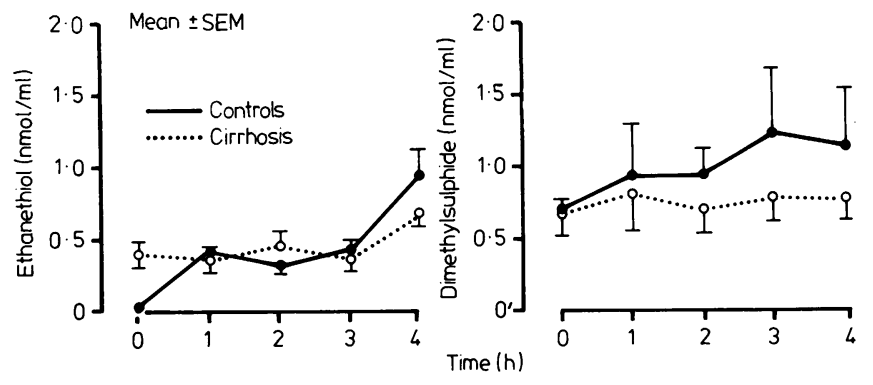

and dimethylsulphide in rats treated with carbon tetrachloride are shown in Table 3. Blood concentrations (previously reported ${ }^{10}$ ) are also shown. Brain concentrations were similar to controls. For methanethiol simultaneous blood concentrations were significantly increased but this did not lead to a rise in brain concentration.

\section{METHANETHIOL INDUCED COMA}

Concentrations of mercaptans in blood and brain in rats treated with intraperitoneal methanethiol (40$120 \mu \mathrm{mol}$ ) are shown in Figures 4 and 5. Rats were divided into those remaining awake, those just unable to stand but not comatose, and those in coma within three minutes of administration. When rats in coma were left they regained consciousness over the succeeding 15 minutes. Rats were killed three minutes after methanethiol if still awake or sooner if comatose.

Blood methanethiol concentrations in rats remaining awake were considerably greater than in patients with hepatic coma (Fig. 4). Rats just unable to stand and those in coma showed even higher concentrations so that the threshold for coma appeared to be associated with a blood concentration about 10-fold greater than in patients with hepatic coma. There was considerable overlap in the brain concentrations of methanethiol, some rats in coma having concentrations similar to those seen in rats which were awake (Fig. 4).

Dimethylsulphide concentrations in blood in rats

BRAIN CONCENTRATIONS OF MERCAPTANS

Brain concentrations of methanethiol, ethanethiol,

Table 1 Concentrations of mercaptans in blood and brain of germ free and control rats (mean $\pm S E M$ )

\begin{tabular}{|c|c|c|c|c|c|c|}
\hline & \multicolumn{3}{|c|}{ Blood $(\mu \mathrm{mol} / \mathrm{l})$} & \multicolumn{3}{|c|}{ Brain (nmollg wet weight) } \\
\hline & $M T$ & $E T$ & $D M S$ & $M T$ & $E T$ & $D M S$ \\
\hline $\begin{array}{l}\text { Germ free rats }(6) \\
\text { Controls }(8)\end{array}$ & $\begin{array}{l}9 \cdot 2 \pm 1 \cdot 1 \\
7 \cdot 0 \pm 0 \cdot 3\end{array}$ & $\begin{array}{l}0 \cdot 3 \pm 0 \cdot 1 \\
0 \cdot 1 \pm 0 \cdot 05\end{array}$ & $\begin{array}{l}0.9 \pm 0.4 \\
1 \cdot 1 \pm 0 \cdot 4\end{array}$ & $\begin{array}{l}7 \cdot 9 \pm 0 \cdot 8 \\
7 \cdot 3 \pm 0 \cdot 6\end{array}$ & $\begin{array}{l}1 \cdot 6 \pm 0 \cdot 1 \\
1 \cdot 0 \pm 0 \cdot 3\end{array}$ & $\begin{array}{l}1 \cdot 8 \pm 0 \cdot 2 \\
0 \cdot 8 \pm 0 \cdot 2^{*}\end{array}$ \\
\hline
\end{tabular}

$* \mathrm{p}<0.01$.

$\mathrm{MT}=$ methanethiol; ET $=$ ethanethiol; DMS $=$ dimethylsulphide. 
Table 2 Blood mercaptans in normal subjects and patients with liver disease ( $\mu$ molll; mean $\pm S E M$ )

\begin{tabular}{lcll}
\hline & $M T$ & $E T$ & $D M S$ \\
\hline Patients with liver disease & & & \\
Without & & & \\
encephalopathy (35) & $7 \cdot 7 \pm 1 \cdot 1$ & $0 \cdot 19 \pm 0 \cdot 05$ & $0 \cdot 57 \pm 0.09$ \\
With encephalopathy (47) & $13 \cdot 2 \pm 1 \cdot 0^{*}$ & $0 \cdot 35 \pm 0 \cdot 05$ & $0 \cdot 62 \pm 0.06$ \\
Normal subjects (29) & $5 \cdot 7 \pm 0 \cdot 3$ & $0 \cdot 30 \pm 0 \cdot 05$ & $0 \cdot 42 \pm 0 \cdot 04$ \\
\hline
\end{tabular}

${ }^{*} \mathrm{p}<0.05$

treated with methanethiol were considerably increased (Fig. 5), suggesting rapid conversion of methanethiol in vivo to dimethylsulphide. Brain concentrations were also increased, but concentrations in rats which were awake overlapped with those seen in comatose rats (Fig. 5).

\section{BLOOD AMMONIA CONCENTRATIONS}

Simultaneous blood ammonia and methanethiol concentrations in patients with hepatic coma are shown in Figure 6. There was no correlation between ammonia concentrations and methanethiol $(\mathrm{r}=0 \cdot 164)$.

In nine patients sequential observations during different grades of coma showed that methanethiol concentrations were always higher in the more severe grade of coma (Fig. 7). These differences, however, were small and were of no value in predicting the coma grade.

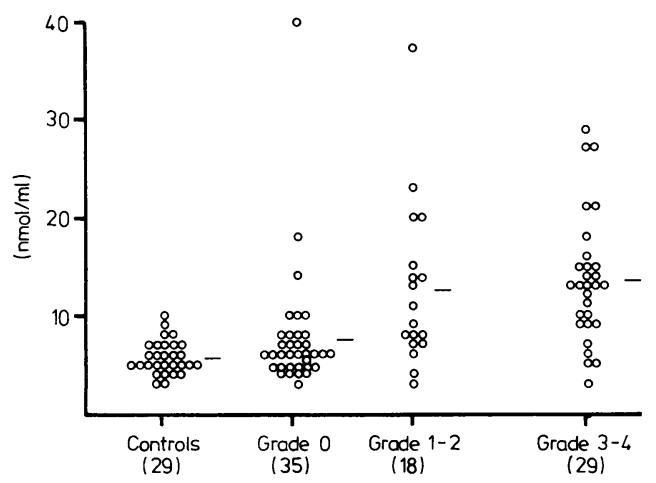

Fig. 3 Blood methanethiol concentrations in control subjects and patients with different grades of hepatic encephalopathy. Mean values are shown by solid bars with number of observations in parenthesis. There were no significant differences between any groups. Coma was graded as described by Trey and Davidson. ${ }^{11}$

\section{Discussion}

In the present study we have extended the previous observations of Doizaki and Zieve ${ }^{12}$ and McClain ${ }^{8}$ to include determinations of ethanethiol and dimethylsulphide in the blood and have also measured all three mercaptans in the brain. Unfortunately, these earlier studies were marred by the variable recovery of methanethiol from blood which ranged from $25-80 \%$, higher recoveries being found with the higher blood concentrations. The present studies have used an improved gas chromatographic method in which recovery was constant over a wide concentration range. ${ }^{10}$ Using this method blood methanethiol concentrations in normal man were 10 -fold higher than that reported by $\mathrm{McClain}^{8}$ but were 10 -fold lower than that found by Brunner and Scharff. ${ }^{13}$ Because of the wide discrepancy between our normal range and that found by others we have determined the minimum blood concentration of methanethiol which was associated with coma after administration to rats. By injecting between 40 and $120 \mu \mathrm{mol}$ of methanethiol a range of responses was obtained which varied between normal consciousness, just able to maintain upright posture, and coma. The minimum blood concentration of methanethiol which was associated with coma was $200 \mu \mathrm{mol} / \mathrm{l}$ while the mean concentration in patients with hepatic encephalopathy was $14.5 \mu \mathrm{mol} / 1$, the highest value observed in patients with liver disease being $40 \mu \mathrm{mol} / \mathrm{l}$. Zieve et al ${ }^{1}$ have suggested that methanethiol, ammonia, and short chain fatty acids act synergistically and that subcoma doses of each given individually are able to induce coma when given together. When subcoma doses of methanethiol were given with ammonia or short chain fatty acids and coma resulted, however, blood concentrations of methanethiol were similar to those in rats given sufficient methanethiol alone to produce coma. It has previously been suggested that rats with such artificial coma exhibited similar concentrations of methanethiol in blood to rats and man with hepatic encephalopathy ${ }^{8}{ }^{12}$ but the present findings do not support this view, a 10-fold difference being found. Acute changes in the rat following methanethiol administration may not be comparable to the more slowly evolving hepatic coma in man. This factor, however, is unlikely to account for the large differences in blood methanethiol concentrations associated with coma in the two groups.

Previous studies ${ }^{8}$ have suggested that methanethiol determinations are valuable in patients with hepatic coma. In the present study we have found considerable overlap in the blood concentrations of methanethiol in patients with different grades of coma and control subjects. Indeed the highest 
Table 3 Concentrations of mercaptans in blood and brain of rats treated with carbon tetrachloride $(3 \cdot 2 \mathrm{~g} / \mathrm{kg})$ and controls

\begin{tabular}{|c|c|c|c|c|c|c|}
\hline & \multicolumn{3}{|l|}{ Blood } & \multicolumn{3}{|l|}{ Brain } \\
\hline & $M T$ & $E T$ & $D M S$ & $M T$ & $E T$ & $D M S$ \\
\hline Carbon tetrachloride & $\begin{array}{l}12 \cdot 5 \pm 0 \cdot 8^{*} \\
(14)\end{array}$ & $\begin{array}{l}0 \cdot 1 \pm 0 \cdot 1 \\
(14)\end{array}$ & $\begin{array}{l}1 \cdot 6 \pm 0.4 \\
(14)\end{array}$ & $\begin{array}{l}7 \cdot 8 \pm 0 \cdot 4 \\
(12)\end{array}$ & $\begin{array}{l}1 \cdot 4 \pm 0 \cdot 2 \\
(12)\end{array}$ & $\begin{array}{l}1 \cdot 1 \pm 0 \cdot 1 \\
(12)\end{array}$ \\
\hline Controls & $\begin{array}{l}7 \cdot 0 \pm 0.3 \\
(9)\end{array}$ & $\begin{array}{l}0.1 \pm 0.05 \\
(9)\end{array}$ & $\begin{array}{l}1 \cdot 1 \pm 0 \cdot 4 \\
(9)\end{array}$ & $\begin{array}{l}7 \cdot 3 \pm 0 \cdot 6 \\
(8)\end{array}$ & $\begin{array}{l}1 \cdot 0 \pm 0 \cdot 3 \\
(8)\end{array}$ & $\begin{array}{l}0 \cdot 8 \pm 0 \cdot 2 \\
(8)\end{array}$ \\
\hline
\end{tabular}

Concentrations of mercaptans are expressed as $\mu \mathrm{mol} / \mathrm{l}$ for blood and $\mathrm{nmol} / \mathrm{g}$ wet weight for brain, as mean $\pm \mathrm{SEM}$ with number observations in parenthesis. Values for carbon tetrachloride treated rats which are statistically different from controls are indicated by ${ }^{*} \mathrm{p}<0 \cdot 001$.

Rats were killed $24 \mathrm{~h}$ after carbon tetrachloride administration or sooner if moribund.

Fig. 4 Methanethiol concentrations in blood and brain of rats after intraperitoneal injection. Rats were divided into those which were fully awake, those just able to stand, and those which were comatose.
Fig. 5 Dimethylsulphide concentrations in blood and brain of rats after intraperitoneal injection of methanethiol. Rats were divided into those which were awake, those just able to stand, and those in coma.
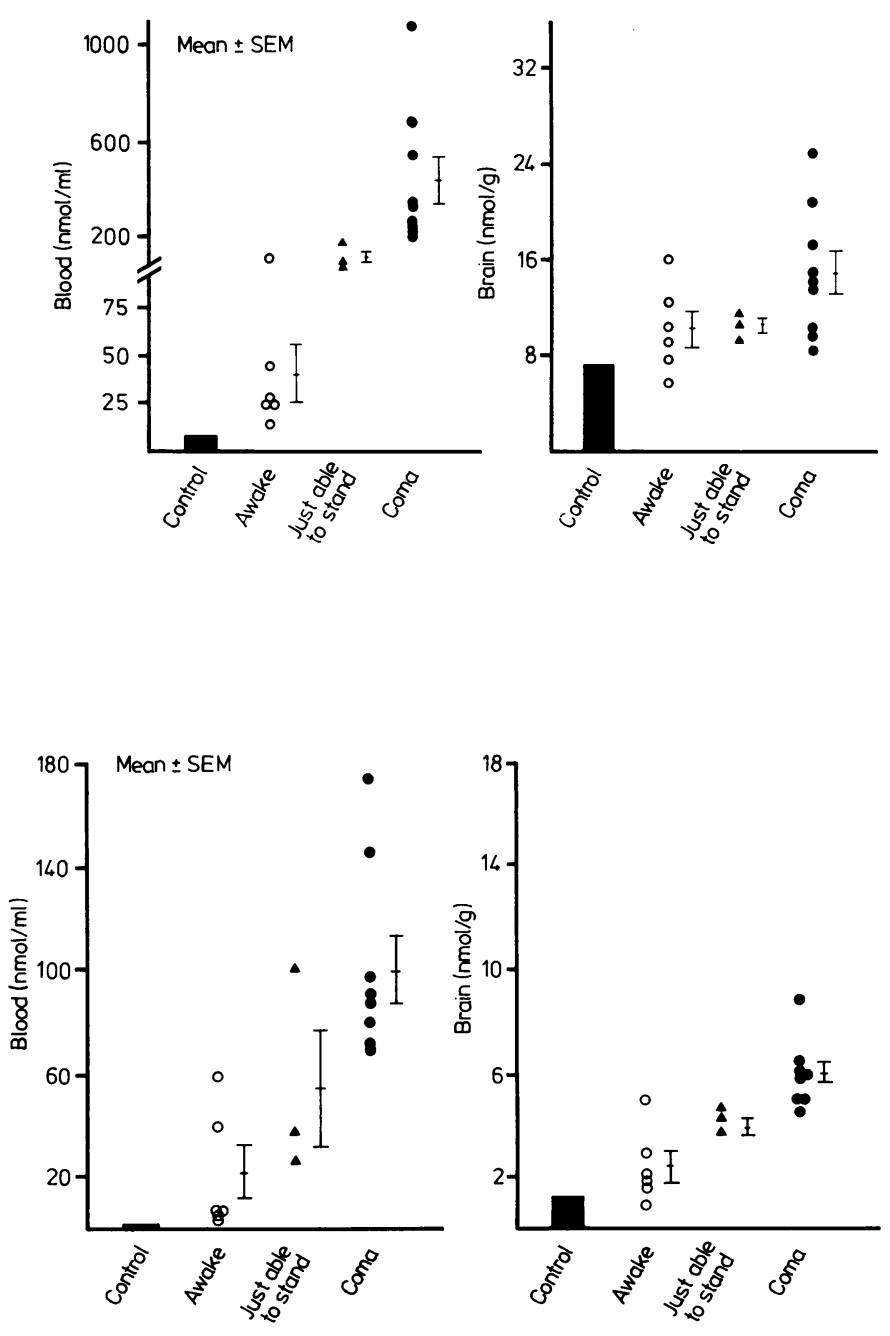


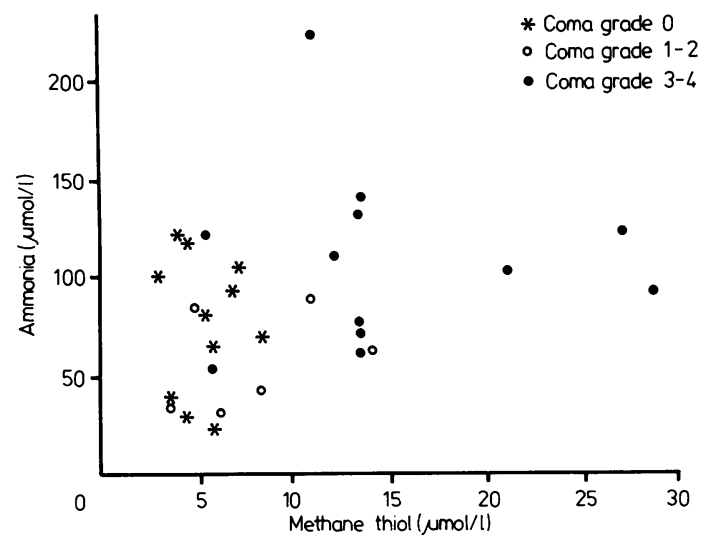

Fig. 6 Relationship between ammonia and methanethiol concentrations in patients with hepatic encephalopathy. Correlation was not significant $(r=0 \cdot 164)$. The coma was graded as described by Trey and Davidson. ${ }^{11}$

concentration was found in a non-comatose outpatient with primary biliary cirrhosis. The mean concentration of methanethiol in encephalopathic patients, however, was significantly increased compared to non-encephalopathic patients and controls but ethanethiol and dimethylsulphide concentrations were similar in all groups. Blood ethanethiol concentrations were similar to those previously associated with coma in the rat $(0 \cdot 2$ $\mu \mathrm{mol} / \mathrm{l})^{1}$ while blood dimethylsulphide concentrations were very much lower than those associated with coma in the rat $(7 \mathrm{mmol} / \mathrm{l}) .{ }^{1}$ Valid comparisons between these figures cannot be made because of methodological differences. Both in the present

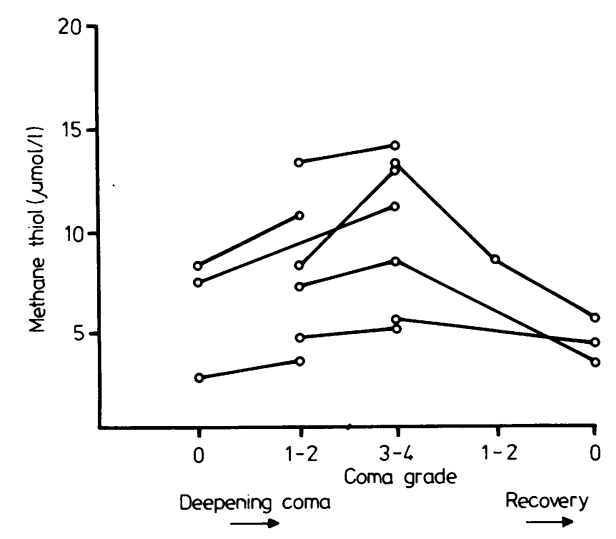

Fig. 7 Sequential methanethiol concentrations in nine patients with hepatic encephalopathy. Encephalopathy was graded as described by Trey and Davidson. ${ }^{11}$ studies and those of $\mathrm{McClain}^{8}$ there was no correlation between blood ammonia and methanethiol concentrations.

Phear et $\mathrm{al}^{14}$ showed neuropsychiatric changes in cirrhotics fed methionine, an effect which occurred without change in blood ammonia concentrations and which could be prevented by the administration of chlortetracycline. Patients developing encephalopathy received a mean of $27 \mathrm{~g}$ methionine over two and a half days. It was suggested that this effect of methionine was due to a toxic breakdown product other than ammonia. In the present study blood methanethiol, ethanethiol, and dimethylsulphide did not change significantly after ingestion of $2 \mathrm{~g}$ of methionine and decreased concentrations were not observed in germ free rats. It thus seems unlikely that bacterial metabolism in the gut is the major source of engdogenous mercaptans in man. Whether methanethiol was the toxic metabolite of methionine postulated by Phear ${ }^{14}$ cannot be determined from the present study because of the large difference in methionine dose administered.

Brain concentrations in rats in coma were significantly greater than in control rats but there was considerable overlap between rats treated with methanethiol which remained awake and those which went into coma. This suggests coma after methanethiol is not induced by this substance alone but that other factors are necessary. Whether methanethiol blocks neurotransmission or induces a metabolic modification in the brain is unknown.

Dimethylsulphide concentrations rose sharply after methanethiol administration suggesting endogenous conversion to dimethylsulphide in the circulation. This could account for the rise in dimethylsulphide concentrations in breath which has been reported in patients with cirrhosis. ${ }^{7}$

The present studies do not suggest that mercaptans play an important role in the pathogenesis of hepatic encephalopathy. Concentrations of methanethiol are certainly increased in the blood of many patients with hepatic coma but this appears to be the result of the severe derangement of metabolic function which occurs in patients with liver disease.

\section{References}

1 Zieve L, Doizaki WM, Zieve FJ. Synergism between mercaptans and ammonia or fatty acids in the production of coma: a possible role for mercaptans in the pathogenesis of hepatic coma. J Lab Clin Med 1974; 83: $16-27$.

2 Dodsworth, JM, James JH, Cummings MC, Fischer 
JE. Depletion of brain norepinephrine in acute hepatic coma. Surgery 1974; 75: 811-20.

3 Zieve L, Olsen RL. Can hepatic coma be caused by a reduction of brain noradrenline or dopamine? Gut 1977; 18: 688-91.

4 Cuilleret G, Pomier-Layrargues G, Pons F, Cadilhac J, Michel $\mathrm{H}$. Changes in brain catecholamine levels in human cirrhotic hepatic encephalopathy. Gut 1980; 21: 565-9.

5 Challenger F, Walshe JM. Methyl mercaptans in relation to foetor hepaticus. Biochem J 1955; 59: 372-5.

6 Chen S, Zieve L, Mahadevan V. Mercaptans and dimethylsulphide in the breath of patients with cirrhosis of the liver. J Lab Clin Med 1970; 75: 628-35.

7 Kaji H, Hisamura M, Saito N, Murao M. Evaluation of volatile sulfur compounds in the expired alveolar gas in patients with liver cirrhosis. Clin Chem Acta 1978; 85: 279-84.

8 McClain CJ, Zieve L, Doizaki WM, Gilbertstadt S, Onstad GR. Blood methanethiol in alcoholic liver disease with and without hepatic encephalopathy. Gut
1980; 21: 318-23.

9 Holloway CJ, Brunner G, Schmidt E, Schmidt FW. Thiols and hepatic coma. Art Organs 1979; 3: 15-9.

10 Al Mardini H, Bartlett K, Record CO. An improved gas chromatographic method for the detection and quantitation of mercaptans in blood. Clin Chim Acta 1981; 113: 35-41.

11 Trey C, Davidson CS. The management of fulminant hepatic failure. In: Popper $\mathrm{H}$, Schaffner $\mathrm{E}$, eds. Progress in liver disease. New York: Grune and Stratton, 1970, vol 3: 282-98.

12 Doizaki WM, Zieve L. An improved method for measuring blood mercaptans. J Lab Clin Med 1977; 90: 849-55.

13 Brunner G, Scharff P. Untersuchungen uber den diagnostischen Wert der Bestimmung von Mercaptanen im Serum bei Lebererkrankungen. Dtsch Med Wochenschr 1978; 103: 1796-1800.

14 Phear EA, Ruebner B, Sherlock S, Summerskill WHJ. Methionine toxicity in liver disease and its prevention by chlortetracycline. Clin Sci 1956; 15: 93-117. 